\title{
Importance of eelgrass early life history stages in response to oyster aquaculture disturbance
}

\author{
Lorena M. Wisehart ${ }^{1, *}{ }^{\text {, Brett R. Dumbauld }}{ }^{2}$, Jennifer L. Ruesink ${ }^{3}$, Sally D. Hacker ${ }^{1}$ \\ ${ }^{1}$ Oregon State University, Department of Zoology, 3029 Cordley Hall, Corvallis, Oregon 97331-2914, USA \\ ${ }^{2}$ USDA/ARS, Hatfield Marine Science Center, 2030 S.E. Marine Science Drive, Newport, Oregon 97365, USA \\ ${ }^{3}$ University of Washington, Department of Biology, Box 351800, Seattle, Washington 98195, USA
}

\begin{abstract}
Seagrasses are a critical element in many estuaries and act as drivers of abiotic and biotic processes. One species, Zostera marina L., has been declining globally. A potential contributor to this decline is shellfish aquaculture, although we know little about its impacts. On the US west coast, shellfish aquaculture co-occurs with protected eelgrass habitats. Many aquaculture practices constitute a periodic disturbance, and a key concern is eelgrass recovery. We used observations and experiments to understand how oyster aquaculture practices (i.e. dredging [oysters grown on the bottom and harvested mechanically via dredging] and off-bottom longline culture [oysters suspended off the bottom on rope and harvested by hand]) influence eelgrass recovery. Studies of natural recruitment showed highest seedling densities in dredged beds $\left(7\right.$ seedlings $\left.\mathrm{m}^{-2}\right)$ and lowest under longlines $\left(0.1\right.$ seedlings $\left.\mathrm{m}^{-2}\right)$. Seed production was highest in dredged beds $\left(295\right.$ seeds $\left.\mathrm{m}^{-2}\right)$ and lowest in longline beds (52 seeds $\mathrm{m}^{-2}$ ). Seed addition experiments were conducted to understand the effect of oyster aquaculture and adult eelgrass neighbors on seedling germination, growth, and survival. In March 2005, seedling germination was $146 \%$ higher in eelgrass removal treatments compared to control plots, with no difference among aquaculture and reference areas. By April 2005, there were no effects of neighbors, but reference areas had greater seed densities (11 seedlings $\mathrm{m}^{-2}$ ) compared to longline areas $\left(3.2\right.$ seedlings $\mathrm{m}^{-2}$ ). By August 2005, seedling mortality in longline and reference control plots was $100 \%$. In dredged areas, seedlings in removal plots had greater biomass $(0.38 \mathrm{~g})$ than seedlings in control plots $(0.14 \mathrm{~g})$. We propose that if eelgrass is to be disturbed by aquaculture, dredge beds may recover more successfully than longline beds.
\end{abstract}

KEY WORDS: Zostera marina $\cdot$ Crassostrea gigas $\cdot$ Shellfish aquaculture $\cdot$ Disturbance $\cdot$ Seeds Germination · Recovery $\cdot$ Estuary $\cdot$ Willapa Bay

\section{INTRODUCTION}

Seagrasses are among the most productive plants on earth (McRoy \& McMillan 1977, Duarte \& Chiscano 1999) and influence community structure and function through a combination of physical, chemical, and biological mechanisms (Phillips 1984, Thayer et al. 1984). Declining seagrass populations worldwide have been largely due to increases in anthropogenic disturbance (Short \& Burdick 1996) including lowered water quality or clarity, nutrient and sediment loading from runoff and sewage disposal, dredging and filling for navigation, pollution, upland development, and commercial fishing (Fonseca et al. 1984, Short \& Burdick 1996, Short \& Wyllie-Echeverria 1996).
The impacts that aquaculture activities may have on seagrass populations are also of increasing concern (Simenstad \& Fresh 1995, Neckles et al. 2005, Orth et al. 2006a) because of the potential negative effects resulting from both recreational and commercial shellfish harvest, including reduced seagrass biomass, density, and percent cover in harvested areas (Fonseca et al. 1984, Everett et al. 1995, Boese 2002, Orth et al. 2002, Thom et al. 2003, Cabaço et al. 2005, Neckles et al. 2005). Hydraulic dredges used to harvest oysters can cause long-term disruption of eelgrass Zostera marina beds, reducing or even eliminating beds in some cases (Waddell 1964, Phillips 1984). Additional aquaculture activities, including the dumping of shells on eelgrass beds and mechanical raking or trampling, 
are also of concern, although their impacts have not been well documented (NMFS 2001).

There are also examples of positive interactions between shellfish and seagrasses (Reusch et al. 1994, Peterson \& Heck 1999, 2001). When the suspensionfeeding mussel Modiolus americanus (Leach) was added to meadows of Thalassia testudinum (Banks ex König), an increase in sediment nutrients that were biologically available to the seagrass was noted (Peterson \& Heck 2001). The response of $T$. testudinum included increased leaf widths and lengths as well as greater productivity in mussel addition areas, largely due to reduced epiphyte loads on the leaves (Peterson \& Heck 2001).

Shellfish farming is an important industry along the northwest coast of the USA. Washington leads the nation in production of farmed bivalve shellfish, and Willapa Bay, Washington, produces nearly $9 \%$ of the US total oyster harvest (Ruesink et al. 2006). The 2 most common oyster aquaculture methods used in Willapa Bay are ground and longline culture (Quayle \& Newkirk 1989, Conte et al. 1996, Feldman et al. 2000), although the former is much more abundant than the latter. Ground culture involves the placement of oysters directly on the sediment in a single layer (Feldman et al. 2000), which are then harvested by hand or by mechanical dredging. Dredge harvesting typically occurs during winter months, when above-ground shoot densities are lowest; however, some above and below-ground plant structures may still be removed during the harvest dredging operation (Simenstad \& Fresh 1995). Additional ground culture management activities include mechanical harrowing and leveling (Quayle \& Newkirk 1989, Conte et al. 1996). In contrast, longline culture entails suspending oysters above the sediment surface by weaving them into ropes held up by stakes and then harvesting them by hand. In some areas, 'off-bottom' methods (e.g. longlines, stakes, and racks) are implemented due to unsuitable conditions for ground culture (Simenstad \& Fresh 1995); however, in Willapa Bay, both on- and off-bottom culture occur intermixed on tideflats and, over time, even on a single bed (J. Ruesink pers. obs.). In other regions of the country (e.g. in Humboldt Bay, California), regulators have required the use of ground culture be discontinued, and these areas have been replaced with longline culture due to a perceived reduction in negative impacts.

Little is known about the response of vegetative adult stages to aquaculture, and even less is known about the influence on flowering and early life history stages, which we hereafter refer to as recruitment. The few studies that have addressed recruitment have reported contrasting effects. For example, Fonseca et al. (1984) proposed that dredging for scallops in iso- lated eelgrass beds could adversely affect the continuation and/or recovery of that meadow due to a reduction in the number of seeds and seedlings available to aid in recolonization. They ultimately concluded that the sexual and vegetative reproduction of eelgrass meadows could be severely hindered by repeated scallop dredging. More recently, Alexandre et al. (2005) reported an increase in Zostera noltii reproductive effort (proportion of shoot biomass allocated to sexual reproduction) that coincided with a decrease in shoot density following experimental clam harvest.

Eelgrass meadows can grow and persist by vegetative spread (Bell \& Tomlinson 1980, Hemminga \& Duarte 2000), but the establishment of new meadows is controlled by seed recruitment (Orth et al. 2006a). Seeds are especially important in re-establishing meadows that are subject to seasonal perturbations or other disturbances that reduce eelgrass biomass (Thayer et al. 1984, Plus et al. 2003). Dredge harvesting of oysters reduces eelgrass biomass and shoot density, but oyster growers have reported that eelgrass rapidly reappears in areas planted with oysters, anecdotally suggesting that eelgrass recruitment is high into these disturbed areas. There are 2 potential mechanisms to explain high recruitment: (1) oysters influence eelgrass seed production, seed germination, and/ or seedling survival by altering the nutrient or light environment through filter feeding and feces/pseudofeces deposition (Reusch et al. 1994) or by trapping/ protecting seeds, and (2) aquaculture disturbance affects eelgrass seed production, seed germination, and/ or seedling survival by removing neighboring adult eelgrass plants or modifying the physical characteristics of the environment (e.g. loss of fine sediments following dredge harvest). We explored these mechanisms by examining the interaction between oyster aquaculture practices and eelgrass early life history dynamics in Willapa Bay, Washington. We present results from both observational and experimental studies that address the variable impacts of 2 different aquaculture types as well as the relative importance of seed supply, germination success, and adult-seedling interactions in determining patterns of natural recruitment.

\section{MATERIALS AND METHODS}

Study site. Willapa Bay $\left(46^{\circ} 40^{\prime} \mathrm{N}, 124^{\circ} 0^{\prime} \mathrm{W}\right)$ is a coastal estuary ( $260 \mathrm{~km}^{2}$ at mean high water) characterized by broad extensive tideflats and large tidal amplitude. Approximately $21 \%$ of the bay's intertidal ground is commercially farmed and managed for oysters, the dominant species being the Pacific oyster Crassostrea gigas, which is native to Japan (Feldman et al. 2000). Oyster aquaculture occurs at tidal elevations of 
-1 to +1 m mean lower low water (MLLW), which overlap with eelgrass beds (+1.8 and -6.6 m MLLW; Phillips 1984). Although it is generally restricted to the highest intertidal zones, Zostera japonica (Aschers. \& Graebn.), a non-native seagrass species, can also overlap with $Z$. marina (L. Wisehart pers. obs.).

We conducted our studies at Stony Point, a nearshore site in the northeastern section of Willapa Bay. This site is near both the Willapa and Palix Rivers and the mouth of the bay, where it receives considerable sediment deposition and salinities vary between 25 and 32 ppt (Ruesink et al. 2003). Multiple beds (ca. $30 \mathrm{~m}^{2}$ ) of dredged ground culture, off-bottom longline culture, and undisturbed eelgrass are present at Stony Point. Because we were interested in the effect of aquaculture in a natural setting, we used active beds as aquaculture treatments. To avoid confounding bed type with site, we conducted the observations and experiments in 3 separate beds of each aquaculture type based on similarity of tidal height and bed age. Three additional undisturbed eelgrass beds (reference areas) were selected following similar criteria. We were limited to 3 beds per aquaculture type due to the number of dredge beds available.

Zostera marina phenology in Willapa Bay follows a pattern of low biomass and density in winter months (November to January) and high productivity in the spring and summer months. Peak seed germination occurs in April and early May, followed by the appearance of reproductive shoots in July with the majority of seed release occurring in August (L. Wisehart unpubl. data).

Natural eelgrass seedling recruitment and seed supply. To quantify eelgrass seedling recruitment under different aquaculture types, we surveyed seedlings in April 2005. In each bed, 30 quadrats $\left(0.25 \mathrm{~m}^{2}\right)$ were haphazardly (i.e. their placement was not based on the use of a random number table; Gotelli \& Ellison 2004) tossed across the entire sample area and the number of Zostera marina seedlings, the number of adult shoots, the percent cover of benthic oysters, and the percent cover of macroalgae were recorded (30 subsamples for each aquaculture type and reference area $\times 3$ replicate beds). Quadrats were placed without regard to where they would fall within the bed type, because we wanted to cover as much of the bed as possible. Oysters on the longlines were not included in the percent cover estimates of benthic oysters. Z. marina seedlings were distinguished from adult $Z$. marina and $Z$. japonica individuals by carefully digging them up and confirming the absence of an established rhizome.

We surveyed flowering shoot densities in July 2005, during peak flowering, by haphazardly tossing 50 quadrats $\left(0.25 \mathrm{~m}^{2}\right)$ in each of the beds surveyed for seedlings (50 subsamples for each aquaculture type and the reference area $\times 3$ replicate beds). In addition,
30 flowering shoots were haphazardly collected and returned to the lab to estimate potential seed production. We counted the number of spathes per shoot and multiplied that by the average number of seeds per spathe (seeds included total number of female flowers [ovaries] and fruits [fertilized ovaries]). We then estimated the number of seeds produced per $0.25 \mathrm{~m}^{2}$ by multiplying the number of flowering (seed producing) shoots per quadrat by the mean number of seeds produced per plant for that aquaculture type. Our estimates of potential seed production are not absolute values but relative values among the beds; actual seed production is likely lower because only a portion of the ovaries may have produced viable seeds.

In January 2006, we surveyed Zostera marina seeds in the sediment (after all seeds had been released from the flowering shoots, but prior to germination). Five cores $(10 \mathrm{~cm}$ diameter $\times 15 \mathrm{~cm}$ depth) were haphazardly collected from each bed (5 subsamples for each aquaculture type and the reference area $\times 3$ replicate beds). The samples were sieved in the field using a $0.5 \mathrm{~mm}$ sieve and counted in the lab. Data presented are total seed bank estimates and thus include both viable (rigid seed coat and embryo development) and non-viable (50\% or more of seed coat) seeds (Harwell $\&$ Orth 2002).

Experimental manipulations of eelgrass recruitment. To understand whether germination would vary under different aquaculture types and in the presence of eelgrass neighbors, we conducted an eelgrass seedaddition experiment. In August 2004, we collected seed-bearing shoots from several sites throughout Willapa Bay and transferred them to large outdoor tanks partially filled with seawater. Once seeds fell from the parent plants, they were collected from the bottom of the tanks and stored at $4^{\circ} \mathrm{C}$ in filtered seawater in the dark until planting in September 2004. A matched pair layout (Gotelli \& Ellison 2004) was employed to reduce heterogeneity with paired eelgrass removal and control treatment plots $\left(0.25 \mathrm{~m}^{2}\right)$ chosen haphazardly in 3 beds of each aquaculture type and reference area described above. Packets containing 30 seeds each were secured with wire stakes directly on top of the sediment in each plot $(5$ subplots per treatment for each of the aquaculture types and reference area $\times 3$ replicate beds). Seed packets were $10 \mathrm{~cm}$ in diameter and constructed of fabric mesh (3 mm opening) with an inner envelope of biodegradable paper (Dethier \& Hacker 2005). The purpose of the inner envelope was to retain the seeds in the packets during transport and sowing. Over the course of the winter, sediment was deposited on top of the packets, the paper envelopes degraded, and the seeds were naturally buried in situ. The large mesh size easily allowed for germination of seeds and seedling growth 
through the mesh, and the packet served as a landmark allowing us to distinguish experimentally added seeds from those recruiting into the plots naturally. To maintain the eelgrass removal treatment, adult plants inside the removal plots were pulled initially in September 2004, and also in March, April, and June 2005.

Seed germination and seedling survival in the packets were monitored in March, April, June, and August 2005. In March, we discovered that 5 paired plots had been destroyed when one of the ground culture beds had been dredged. This changed the number of dredged beds to 2 (the longline and reference area subsample size remained at 5 paired plots $\times 3$ replicate beds). To monitor seedling emergence and survival, a 'table' was constructed with PVC pipe as the frame and a transparent Plexiglass sheet as the top $(22 \times$ $25 \mathrm{~cm}$ ). The table was placed over the mesh packets at each plot, an acetate sheet was laid on the Plexiglass sheet, and the location and number of $Z$. marina seedlings and adults were marked with permanent ink. In August 2005, packets were carefully dug up and seedlings were removed, measured for length (cm), and dried for biomass (g). In April and August 2005, the number of Zostera marina shoots, seedlings, and the percent cover of oysters and algae were recorded for each of the $0.25 \mathrm{~m}^{2}$ seed addition plots.

Physical characteristics. Sediment characteristics were measured in the different aquaculture types and reference areas in April 2005 when the seedlings first emerged. Sediment redox potential was measured at $4 \mathrm{~cm}$ depth in each of the seed addition plots $(5 \mathrm{sub}-$ samples for each aquaculture type and the reference area $\times 3$ replicate beds) using a redox meter fitted with a platinum redox electrode and filled with $\mathrm{AgCl}$ solution (Thermo Orion). Sediment grain size (silt to sand ratio) was determined by haphazardly collecting 3 sediment samples ( $50 \mathrm{~g})$ from the sediment surface of the beds described above ( 3 subsamples for each aquaculture type and reference area $\times 3$ replicate beds). The samples were weighed before and after drying and wet sieving through a $63 \mu \mathrm{m}$ sieve followed by a $2 \mathrm{~mm}$ sieve ( 0 to $63 \mu \mathrm{m}=$ silt, $63 \mu \mathrm{m}$ to $2 \mathrm{~mm}=$ sand). In addition, sediment accretion was determined by measuring the depth of sediment on top of the seed packets in June 2005, based on the average of 3 measurements per packet.

Statistical analyses. Differences in natural seedling density, adult eelgrass shoot density, flowering shoot density, seed production, seed density in sediments, and percent cover of oysters and macroalgae among aquaculture types were tested using 1-factor nested analyses of variance (ANOVAs; with bed nested in aquaculture type). The relationship between oyster cover and seedling density was analyzed with linear regression.
For the seed addition experiment, a 2-factor nested ANOVA was used to test for the effects of eelgrass removal treatment, aquaculture type (with bed nested in aquaculture type), and their possible interaction, on seedling density. All longline plots and the control reference plots had complete death of seedlings (via natural causes) by the end of the experiment, thus leading to unbalanced designs. As such, 1-factor ANOVAs were used to test for differences in seedling length and biomass among the remaining treatments. We used 1-factor nested ANOVAs (with bed nested in aquaculture type) to test for differences in redox potential, sediment grain size, and sedimentation among the aquaculture types and the reference. Scheffé's multiple comparisons test was used to examine all significant factors $(\mathrm{p}<0.05)$. Data were transformed when necessary (Gotelli \& Ellison 2004), although untransformed values are shown in the figures. Analyses were run using NCSS 2001 (NCSS, Kaysville).

\section{RESULTS}

\section{Natural eelgrass seedling recruitment and seed supply}

The density of Zostera marina seedlings varied significantly among the aquaculture types and the reference area (Fig. 1A $; 1$-factor nested ANOVA; $F_{8,261}=$ 4.0, $\mathrm{p}=0.0002$ ). Significantly fewer seedlings were observed in the longline beds compared to the dredged and reference beds, which did not significantly differ. In contrast, the density of adult eelgrass shoots was greatest in the reference areas compared to the longline and dredged areas, which did not differ (Fig. 1B; 1-factor nested ANOVA; $F_{8,261}=17.4, \mathrm{p}=$ $0.0001)$. Benthic oyster abundance was greatest in the dredged beds compared to the longline and eelgrass beds, which did not differ (Fig. 1C; 1-factor nested ANOVA $; F_{8,261}=37.5, \mathrm{p}=0.0001$ ). However, the number of naturally occurring eelgrass seedlings was negatively correlated with percent cover of Crassostrea gigas in dredged areas (Fig. 2). Macroalgal cover was also greatest in the dredged beds (Fig. 1D; 1-factor nested ANOVA; $F_{8,261}=13.2, \mathrm{p}=0.001$ ).

Flowering shoot densities were similar among dredged, longline, and eelgrass reference areas (Fig. 1E; 1-factor nested ANOVA; $F_{8,454}=1.5, \mathrm{p}=$ $0.1517)$. However, potential seed production varied significantly between the aquaculture types and reference areas (Fig. 1F; 1 -factor nested ANOVA; $F_{8,454}=$ 2.0, $\mathrm{p}=0.0502$ ). More seeds were produced in the dredged beds than in the reference beds, and lowest seed production occurred in the longline beds. Seed bank densities were also greatest in the dredged areas 

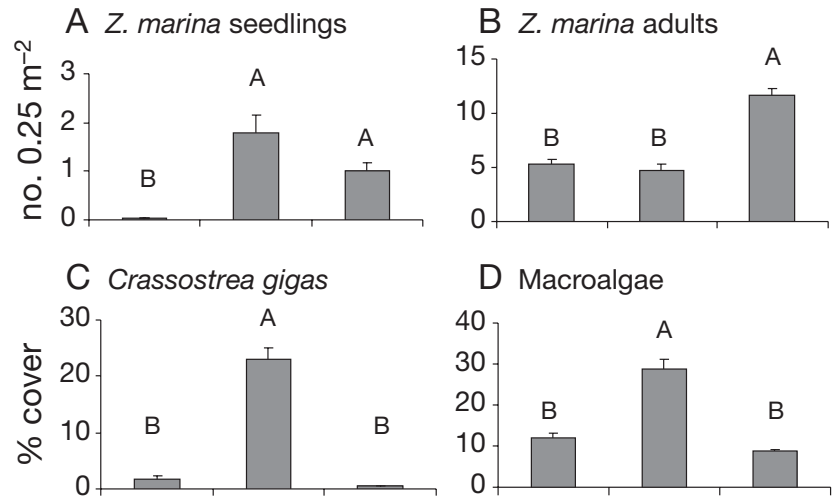

E Z. marina flowering shoots

F Z. marina seed production
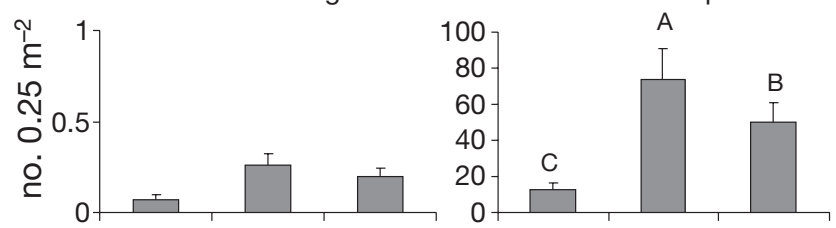

Longlines Dredged Reference

G Z. marina seeds in sediment

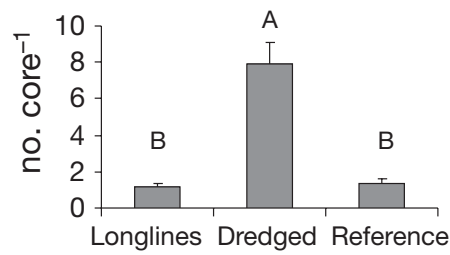

Fig. 1. Density of Zostera marina (A) seedlings and (B) adult shoots and percent cover of (C) Crassostrea gigas oysters and (D) macroalgae per $0.25 \mathrm{~m}^{2}$ in different aquaculture types at Stony Point, Willapa Bay, Washington, April 2005. (E) Density of $Z$. marina flowering shoots and $(\mathrm{F})$ potential seed production per $0.25 \mathrm{~m}^{2}$, July 2005. (G) Mean number of $Z$. marina seeds in sediment cores $(10 \times 15 \mathrm{~cm})$, January 2006 . Values represent means \pm 1 SE. Letters indicate significant differences as indicated by Scheffé's multiple comparison test

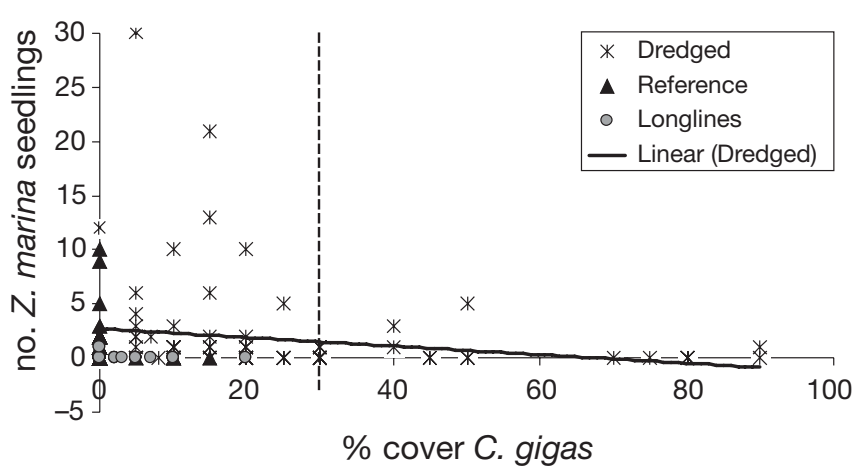

Fig. 2. Relationship between density of naturally occurring Zostera marina seedlings and percent cover of Crassostrea gigas in different aquaculture types. Dashed line indicates target $C$. gigas cover in aquaculture beds. Equation for best fit line of dredged is $y=-0.0396 x+2.6839, R^{2}=0.0346$ with similar but lower seed densities observed in the longline and reference areas (Fig. 1G; 1 -factor nested ANOVA: $\left.F_{8,36}=6.6, \mathrm{p}=0.0001\right)$.

\section{Experimental manipulations of recruitment}

The number of seedlings in the packets varied between control and eelgrass removal treatments and among aquaculture types depending on date (Fig. 3AC). In March, seedling densities were $146 \%$ higher in eelgrass removal treatments compared to control plots (averaged across all aquaculture types). A 2-factor nested ANOVA revealed a significant aquaculture type effect $\left(F_{6,54}=4.7, \mathrm{p}=0.0007\right)$ and an eelgrass removal effect $\left(F_{1,54}=14.3, \mathrm{p}=0.0004\right)$, but there was no significant interaction between the 2 factors $\left(F_{6,54}=\right.$ $1.5, \mathrm{p}=0.1950)$. Seedling densities in April also varied significantly among aquaculture types $\left(F_{7,64}=8.5, \mathrm{p}=\right.$ $0.0001)$, although there was no longer an eelgrass removal effect $\left(F_{1,64}=0.1, p=0.7885\right)$. There were

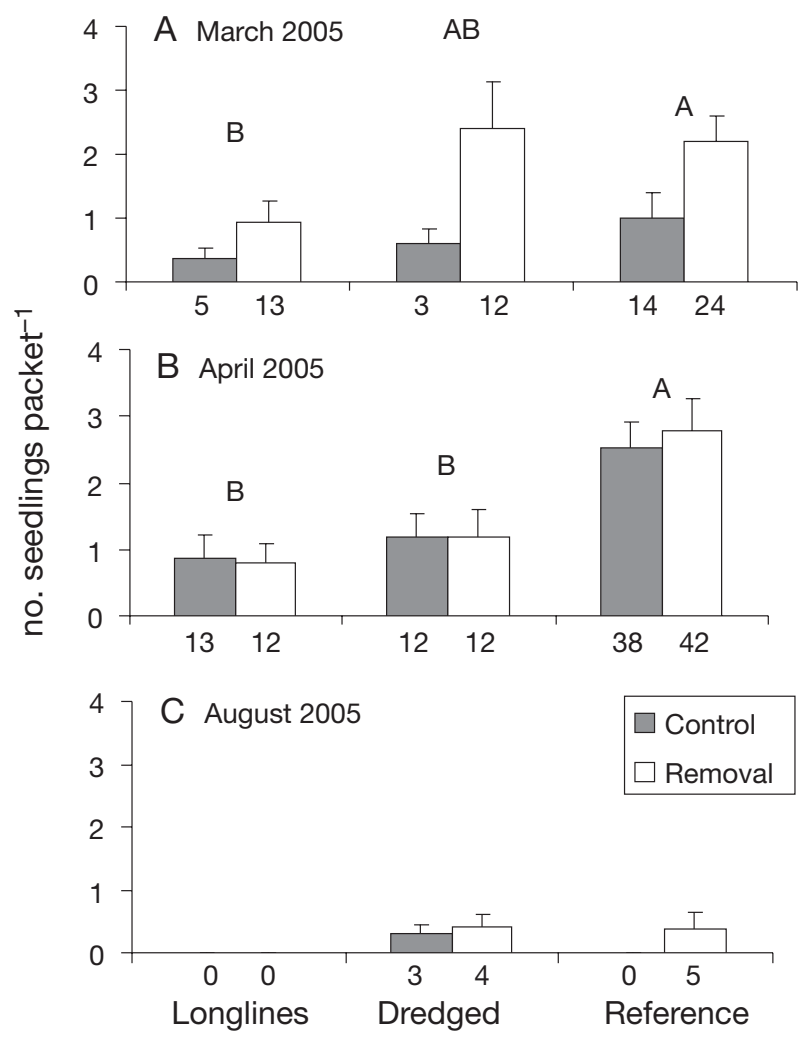

Fig. 3. Zostera marina. Seedling densities in (A) March, (B) April, and (C) August of 2005 in control and eelgrass removal treatments in different aquaculture types and reference areas at Stony Point, Willapa Bay, Washington. Values represent means $\pm 1 \mathrm{SE}$. Letters represent significant differences between longline, dredged, and reference areas (Scheffé's multiple comparison test). Numbers below bars represent total number of seedlings in the sample 
significantly more seedlings in the reference beds compared to the longline beds (Scheffé's $\mathrm{p}<0.05$ ). The interaction between culture type and eelgrass removal was not significant $\left(F_{7,64}=0.9, \mathrm{p}=0.5246\right)$. By August, seedling densities were similar among longline, dredged, and eelgrass reference areas, and there was no difference between control and eelgrass removal treatments (site: $F_{7,61}=1.5, \mathrm{p}=0.2005$; treatment: $F_{1,61}=$ $3.0, \mathrm{p}=0.0905$; interaction: $F_{7,61}=0.9, \mathrm{p}=0.4853$ ).

In August, seedling length and biomass in eelgrass removal treatments were similar between reference and dredged areas, whereas the control plots in the dredged areas had smaller seedlings (Fig. 4A,B). Seedling length did not differ significantly between dredged and reference areas or between control and eelgrass removal treatments (1-factor ANOVA: dredged control vs. dredged removal, $F_{1,4}=3.4, \mathrm{p}=$ 0.139 ; dredged removal vs. reference removal, $F_{1,9}=$ $0.1, \mathrm{p}=0.761$; dredged control vs. reference removal, $\left.F_{1,9}=2.3, \mathrm{p}=0.166\right)$. The difference in seedling biomass between dredged control and eelgrass removal

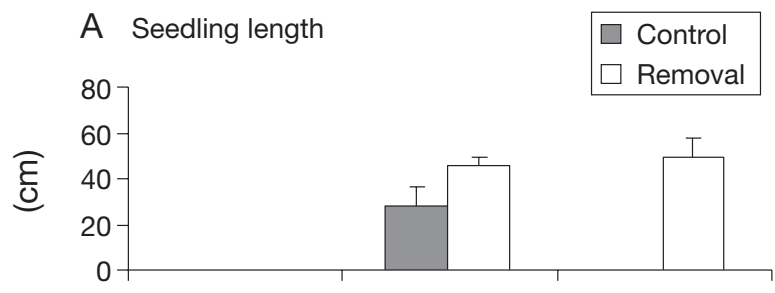

$B$ Seedling biomass
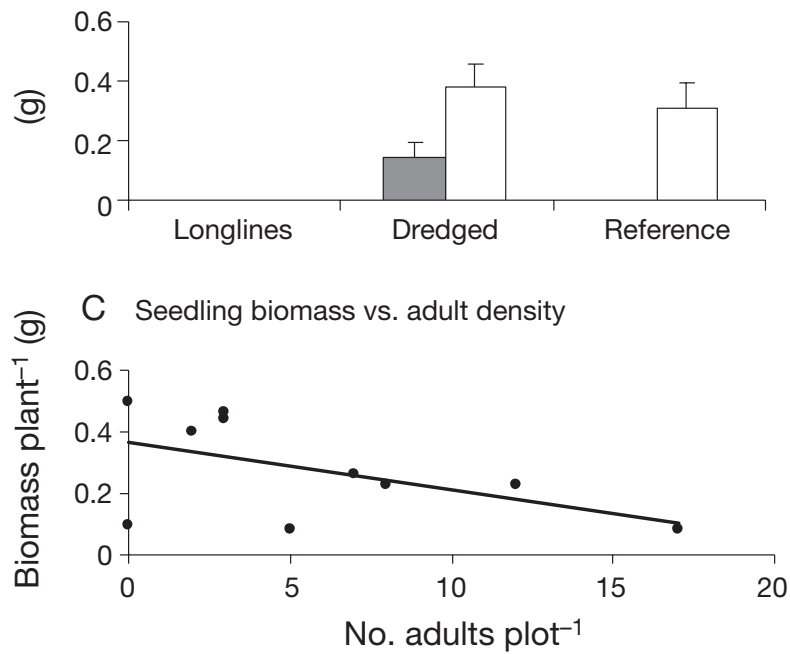

Fig. 4. Zostera marina. Mean seedling (A) length and (B) biomass for control and eelgrass removal treatments in longline, dredged, and reference areas at the end of a seed addition experiment in August 2005. Scheffé's multiple comparison Zvalue test revealed no significant differences between treatments. Values represent means \pm 1 SE. The relationship between adult shoot density and seedling biomass is given in (C). Equation for best-fit line is $y=-0.0154 x+0.3661, R^{2}=0.2679$ treatments was nearly significant (1-factor ANOVA $F_{1,4}=6.8, \mathrm{p}=0.059$ ), while seedling biomass did not differ significantly between dredged and reference areas (1-factor ANOVA; dredged eelgrass removal vs. reference eelgrass removal, $F_{1,5}=0.3, \mathrm{p}=0.617$; dredged control vs. reference eelgrass removal, $F_{1,5}=$ 2.4, $\mathrm{p}=0.179$ ). A trend toward decreasing seedling biomass with increasing density of adult shoots (Fig. 4C) suggests that seedling biomass (per individual) is negatively correlated with adult density.

In April 2005, adult eelgrass density inside the seed addition plots varied significantly between treatments and among aquaculture types and reference areas (Fig. 5A; 2 -factor nested ANOVA; site: $F_{7,64}=4.8, \mathrm{p}=$ 0.0002 ; treatment: $\left.F_{1,64}=47.5, \mathrm{p}=0.0001\right)$ with a significant interaction between the 2 factors $\left(F_{7,64}=7.1, \mathrm{p}=\right.$ 0.0001). Although there was re-growth of adult plants into the removal treatments, the density of adult plants differed significantly between eelgrass removal and control treatments in reference and longline areas (1-factor ANOVAs; reference: $F_{1}=5.3, \mathrm{p}<0.029$; long-

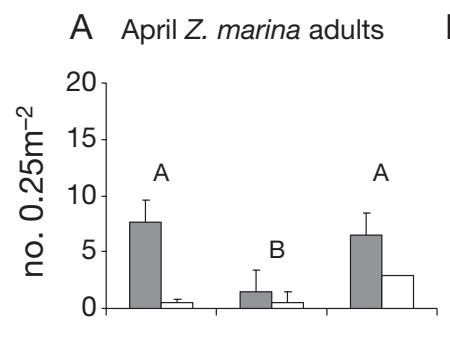

B August $Z$. marina adults

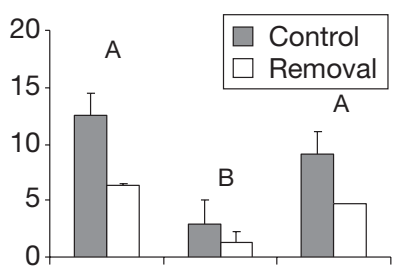

C April macroalgae
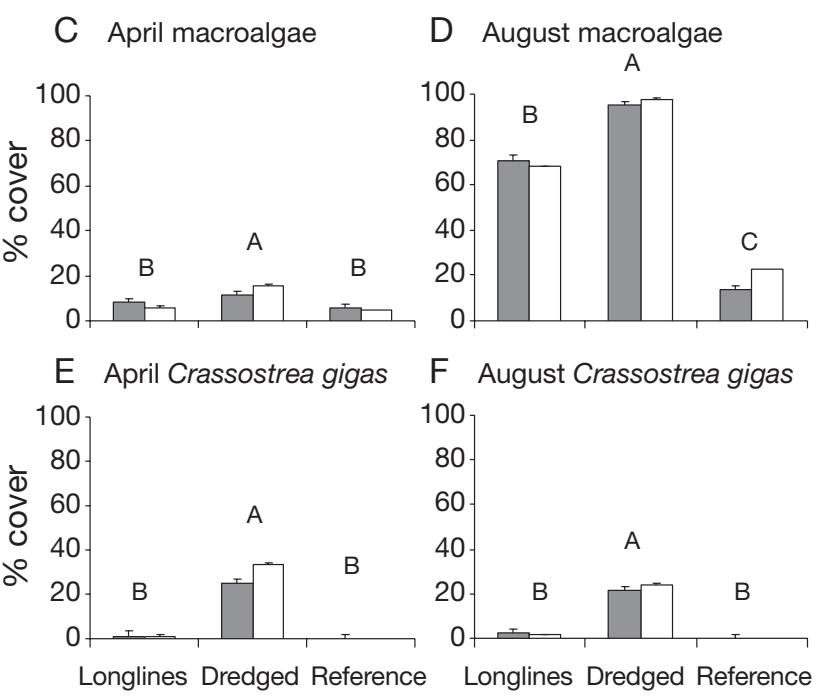

Fig. 5. Density of adult Zostera marina shoots and the percent cover of macroalgae and the oyster Crassostrea gigas in the experimental seed addition plots during 2 sampling periods, April and August 2005. Adult plants were removed from the surrounding $0.25 \mathrm{~m}^{2}$ in the removal plots while controls were left with adult plants present. Letters indicate significant differences between longline, dredged, and reference areas (Scheffé's multiple comparison test) 
lines: $\left.F_{1}=43.2, \mathrm{p}<0.001\right)$. Control plot densities were significantly lower in dredged beds compared to longline and reference areas, and removal plot densities in reference areas were greater than in longline areas (1-factor ANOVA; control: $F_{2}=7.9, p=0.002$; removal: $F_{1}=5.09, \mathrm{p}=0.001$ ). However, adult shoot density did not differ significantly between the control and eelgrass removal treatments in the dredged areas (1-factor ANOVAs; dredged: $F_{1}=1.2, \mathrm{p}=0.281$ ). In August 2005, adult densities varied significantly between control and eelgrass removal treatments as well as between aquaculture and reference areas (Fig. 5B; 2-factor nested ANOVA; site: $F_{7,62}=4.7, \mathrm{p}=0.0003$; treatment: $F_{1,62}=$ $16.0, \mathrm{p}=0.0002$; interaction: $F_{7,62}=3.7, \mathrm{p}=0.0021$ ).

Abundances of macroalgae and oysters in the seedaddition plots varied among the longline, dredged, and reference areas. In April 2005, cover of macroalgae was greatest in dredged beds compared to reference and longline areas (Fig. 5C; 2 -factor nested ANOVA; site: $F_{7,64}=5.2, \mathrm{p}=0.0001$; treatment: $F_{1,64}<0.1, \mathrm{p}=0.9750$; interaction: $\left.F_{7,64}=0.7, p=0.7084\right)$. In August 2005, cover of macroalgae was also greatest in dredged beds (Fig. 5D; 2-factor nested ANOVA; site: $F_{7,62}=34.9, \mathrm{p}=$ 0.0001 ; treatment: $F_{1,62}=0.4, \mathrm{p}=0.5369$; interaction: $\left.F_{7,62}=0.8, p=0.6241\right)$. In April 2005, benthic oysters were absent or nearly so in reference and longline beds (but overall abundance was undersampled in longline beds because oysters on lines were not sampled) but abundant in dredged beds (Fig. 5E; 2-factor nested ANOVA; site: $F_{7,64}=15.3, \mathrm{p}=0.0001$; treatment: $F_{1,64}=$ $0.7, \mathrm{p}=0.4071$; interaction: $\left.F_{7,64}=0.4, \mathrm{p}=0.9201\right)$. In August 2005, benthic oyster cover was similar between longline and reference areas but still abundant in dredged areas (Fig. 5F; 2-factor nested ANOVA; site: $F_{7,62}=34.9, \mathrm{p}=0.0001$; treatment: $F_{1,62}=0.4, \mathrm{p}=0.5369$; interaction: $F_{7,62}=0.8, \mathrm{p}=0.6241$ ).

\section{Physical characteristics}

Sediment characteristics varied among aquaculture types. Redox potential in longline beds was significantly lower than in reference areas although eelgrass removal had no effect (Fig. 6A; 2-factor nested ANOVA; site: $F_{7,64}=2.9, \mathrm{p}=0.0107$; treatment: $F_{1,64}=$ $0.3, \mathrm{p}=0.5644$; interaction: $F_{7,64}=1.4, \mathrm{p}=0.2117$ ). Sediment accretion was higher in longline and reference areas compared to dredged beds but did not vary between controls and eelgrass removal plots (Fig. 6B; 2-factor nested ANOVA; site: $F_{7,62}=8.5, \mathrm{p}=0.0001$; treatment: $F_{1,62}=0.9, \mathrm{p}=0.3515$; interaction: $F_{7,62}=0.3$, $\mathrm{p}=0.9516)$. The silt content of sediments in the longline and reference areas was significantly higher than in dredged beds (Fig. 6C; 1-factor nested ANOVA; $\left.F_{8,17}=12.3, \mathrm{p}=0.001\right)$.
A Sediment redox potential

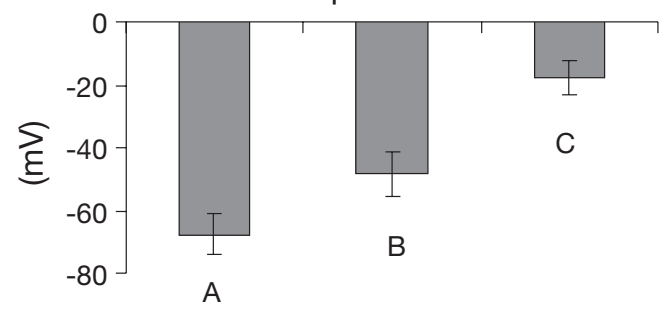

B Sediment accretion

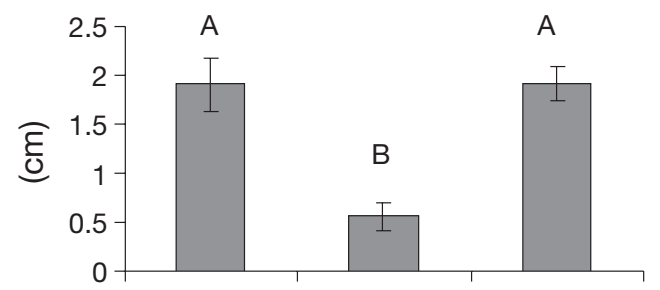

C Sediment silt to sand ratio

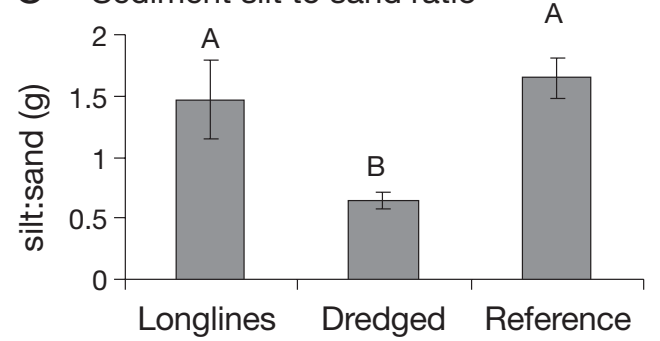

Fig. 6. Mean (A) sediment redox potential, (B) sediment accretion, and $(\mathrm{C})$ sediment silt to sand ratio in longline, dredged, and reference areas. Values represent means $\pm 1 \mathrm{SE}$. Letters indicate significant differences (Scheffé's multiple comparison test)

\section{DISCUSSION}

Our data suggest a strong relationship between oyster aquaculture type and eelgrass seedling success. Observational and experimental results showed that seedlings are most abundant and have higher initial success in dredged beds compared to longline culture areas (Figs. 1A and 3A-C). While we found slightly more seedlings in the dredged beds compared to reference areas, the difference was not significant. Several factors may be driving this pattern, but the most important is likely the presence of adult eelgrass neighbors. We found higher seedling densities in dredged beds that had low density of adult plants compared to reference areas where adult density was significantly greater (Fig. 1B). Furthermore, when neighbors were removed, seedlings survived better (Fig. 3) and were significantly larger (Fig. 4A-C).

Dredge harvest of oysters, which results in decreased eelgrass density due to the removal of aboveground plant structures, may facilitate seed germination and/or seedling growth and survival, by reducing competition for light or other resources. We found a 
positive correlation between removal of adult plants and seedling number in experimental plots. However, adult density may be more important in determining seedling size than population size, as natural seedling densities were unrelated to adult shoot densities. Similar patterns have been observed in eelgrass populations responding to natural disturbances. For example, Robertson \& Mann (1984) found that seed germination was greater in areas where ice scour removed large amounts of aboveground eelgrass biomass, compared to areas where plants were left undisturbed. Robertson \& Mann (1984) also showed negative effects on morphology, growth, and the allocation of seedling biomass to belowground plant parts resulting from competition with adult plants.

We observed very few naturally recruiting seedlings in longline areas, and survivorship of seedlings in longline seed addition plots was zero. The pattern of low seedling abundance in the longline beds and higher densities in dredged areas may be due to differences in seed supply. Our data suggest that seed production and seed bank densities are high in dredged areas compared to longline areas. Low seed densities in longline areas may be related to elevation or other factors associated with the longline structures. Longlines may also act as 'clotheslines,' causing plants to become entwined in the ropes at high tide resulting in severe desiccation at low tide, thus reducing the density of both vegetative and flowering shoots (Pregnall 1993, Everett et al. 1995). Alternatively, higher seed densities in the dredged beds may be due to enhanced seed deposition resulting from removal of adult plants. For example, Inglis (2000) reported high seedling numbers in dugong feeding trails and proposed that this was due to larger densities of seeds in the feeding depressions. Further, seed dispersal and deposition in longline beds may be limited due to altered water flow around the PVC structures.

Aboveground structures in longline areas also have the potential to significantly alter hydrology and sedimentation within the culture area. Grant \& Bacher (2001) developed a numerical model to assess the flow modification induced by suspended aquaculture in China and found that the structures could result in up to $54 \%$ reduction in current speed. The reduction in flow causes longline areas to accrete sediment at much greater rates than would naturally occur (Everett et al. 1995) and could lead to burial of seeds and young seedlings. Seeds that are buried too deeply may not be able to germinate and are then lost to the population (Bigley 1981).

Sediment in the reference and longline plots was composed of a greater percentage of silt than dredged aquaculture areas. This pattern is likely due to a combination of factors. Frequent disturbance in the dredged areas stirs up the sediment and causes a reduction in the amount of fine grain sizes present. Pregnall (1993) reported a significant decline in sediment porosity and fine-grained sediments in groundcultured oyster beds and suggested that the harvest of oysters produces an episodic release of sediments to the estuary. Furthermore, the longline structures and eelgrass blades may cause increased sedimentation by slowing water movement. Redox potential, a proxy for the oxygen content in sediments, might also contribute to trends in germination and seedling survival, as dredged beds had lower redox potential than eelgrass areas but higher seedling densities. Oxygenated sediments may delay or even prevent germination (Moore et al. 1993), which could explain why natural seedling densities were lower in the reference areas. The lowest redox values were observed in longline beds, which could be the result of oyster deposition of organic-rich particles from feces and pseudofeces, changing the microbial community and increasing silt. This could result in increased hypoxia and sediment sulfides, which are toxic for seedlings. This may not occur in dredged beds because water flow in those areas is relatively uninhibited (compared to longline areas), allowing particles to be carried away.

Off-bottom shellfish aquaculture was recommended by the Pew Commission because of a perceived reduction in negative impacts to community structure compared to those of ground culture techniques, which were perceived to create greater disturbance (Kennedy et al. 2002). However, off-bottom culture techniques can also negatively impact adult eelgrass plants (reduced cover; Everett et al. 1995, reduced production), and hinder eelgrass recruitment (Everett et al. 1995, this study). Although there are likely many other contributing factors (e.g. site conditions, differences in dredging equipment and technique, and timing of dredging), restricting or banning all on-bottom culture techniques may not be the best overall strategy. More attention should be paid to the mechanisms of recovery of eelgrass and how these mechanisms interact not only with the type of aquaculture disturbance produced but the spatial and temporal scales over which it occurs (Simenstad \& Fresh 1995, Neckles et al. 2005). Furthermore, future studies should address the role of off-bottom structures in limiting production and/or deposition of seeds and through modification of water flow and physical damage.

Previous work has shown that recovery periods for eelgrass following oyster harvest vary depending on a combination of factors including the type of oyster culture, duration of culture, spatial configuration of culture operations and nearby meadows, and the frequency of oyster harvest events (Waddell 1964, Orth et al. 2002). Our recruitment data suggest that recovery 
via seed germination is possible due to increases in seed production and germination success. Furthermore, enhanced reproductive effort and rapid recovery were reported in Zostera noltii meadows subject to intense recreational clam harvest in southern Portugal (Alexandre et al. 2005, Cabaço et al. 2005). Other studies, however, have reported slower to no recovery following aquaculture activities (Waddell 1964, Peterson et al. 1987, Neckles et al. 2005). These differences could be maintained by larger scale variables such as water quality. For example, the lack of development surrounding Willapa Bay may mean recovery is faster than in more developed estuaries facing water quality problems that could hinder recovery (e.g. shading by excessive algal growth resulting from anthropogenic nutrient loading).

Individual life history characteristics may also play a role in the ability of a species to recover from disturbance. Moloney \& Levin (1996) found that Plantago sp. was able to persist in the presence of very high disturbance rates when at least a few sites that served as seed sources were protected from disturbance. Seagrass recovery in the Delmarva Coastal Bays following significant declines may have been due to propagule supply from remnant stands (Orth et al. 2006b). Furthermore, rapid expansion of recovering populations was likely due in part to high flowering frequency and the potential for short and long-distance dispersal (Orth et al. 2006b). Eelgrass populations subject to disturbance from oyster harvest may respond similarly. Large contiguous eelgrass meadows surrounding the impacted areas may provide a seed source that could facilitate recovery of the disturbed beds. Seed production and germination are also relatively high within adjacent ground-cultured beds, thus serving as a potential seed source following oyster harvest.

Our data have important management implications suggesting that eelgrass recovery is rapid after dredge harvest in oyster culture and that harvest dredge sites may act as sources of eelgrass seed, but we know little about how these results vary among sites (either within or among estuaries). Tidelands used for aquaculture in Willapa Bay comprise a mosaic of disturbance and habitat types. Beds vary in size and use. Some beds are left unmanipulated for the 3 years it takes oysters to reach maturity while other beds are subject to frequent disturbance as oysters are moved on and off-site depending on conditions. Thus some beds may have little to no eelgrass cover due to frequent harvest and management activities while other beds are left unmanipulated for long periods, enabling dense stands of eelgrass to form and persist. Further, little is known about the potential for seeds to travel from one bed to another and how the mosaic of different aquaculture types affects the longer-term sustainability of eelgrass popula- tions. Future studies should examine the site-dependent and landscape-scale effects of oyster aquaculture on eelgrass population dynamics. These issues must be addressed in order to determine whether, and at what scale, no net loss policies should be applied to eelgrass habitat and how industry can respond with best management practices for aquaculture operations.

Acknowledgements. We acknowledge extensive field and laboratory assistance from R. Barker, S. Bradley, M. Briya, J. Grenon, M. Hessing-Lewis, R. Hildenbrand, H. Ibrahim, T. Mac Jones, M. Kavanaugh, L. McCoy, S. Prince, J. Schaefers, A. Trimble, E. Wagner, E. Wheat, and B. and L. J. Wisehart. We also thank J. Kaldy, R. J. Orth, E. Seabloom, and 3 anonymous reviewers for their comments, which greatly improved the quality of this manuscript. This work was made possible by a grant from the Western Regional Aquaculture Center (WRAC) with additional funding from Taylor Shellfish Farms, Inc., and Seattle Shellfish LLC, to B.R.D., J.L.R. and S.D.H. We also thank Coast Seafoods Company for allowing access to the study site.

\section{LITERATURE CITED}

Alexandre A, Santos R, Serrão E (2005) Effects of clam harvesting on sexual reproduction of the seagrass Zostera noltii. Mar Ecol Prog Ser 298:115-122

Bell AD, Tomlinson PB (1980) Adaptive architecture in rhizomatous plants. Bot J Linn Soc 80:125-160

Bigley RE (1981) The population biology of two intertidal seagrasses, Zostera japonica and Ruppia maritima, at Roberts' Bank. MSc thesis, University of British Columbia, Vancouver

Boese BL (2002) Effects of recreational clam harvesting on eelgrass (Zostera marina) and associated infaunal invertebrates: in situ manipulative experiments. Aquat Bot 73: $63-74$

Cabaço S, Alexandre A, Santos R (2005) Population-level effects of clam harvesting on the seagrass Zostera noltii. Mar Ecol Prog Ser 298:123-129

Conte FS, Harbell SC, RaLonde RL (1996) Oyster culture: fundamentals and technology of the West Coast industry. Western Region Aquaculture Center. Pub. No. 94-101. Seattle, WA

Dethier MM, Hacker SD (2005) Physical factors vs. biotic resistance in controlling the invasion of an estuarine marsh grass. Ecol Appl 15:1273-1283

Duarte CM, Chiscano CL (1999) Seagrass biomass and production: a reassessment. Aquat Bot 65:159-174

Everett RA, Ruiz GM, Carlton JT (1995) Effect of oyster mariculture on submerged aquatic vegetation: an experimental test in a Pacific Northwest estuary. Mar Ecol Prog Ser 125: 205-217

Feldman KL, Armstrong DA, Dumbauld BR, Dewitt TH, Doty DC (2000) Oysters, crabs, and burrowing shrimp: review of an environmental conflict over aquatic resources and pesticide use in Washington State's (USA) coastal estuaries. Estuaries 23:141-176

Fonseca MS, Thayer GW, Chester AJ (1984) Impact of scallop harvesting on eelgrass (Zostera marina) meadows: implications for management. N Am J Fish Manag 4:286-293

Gotelli NJ, Ellison AM (2004) A primer of ecological statistics. Sinauer Associates, Sunderland, MA 
Grant J, Bacher C (2001) A numerical model of flow modification induced by suspended aquaculture in a Chinese bay. Can J Fish Aquat Sci 58:1003-1011

Harwell MC, Orth RJ (2002). Seed bank patterns in Chesapeake Bay eelgrass (Zostera marina L.): a bay-wide perspective. Estuaries 25:1196-1204

Hemminga MA, Duarte CM (2000) Seagrass ecology. Cambridge University Press, Cambridge

Inglis GJ (2000) Disturbance-related heterogeneity in the seed banks of a marine angiosperm. J Ecol 88:88-99

Kennedy VS, Twilley RR, Kleypas JA, Cowan JH Jr, Hare SR (2002) Coastal and marine ecosystems and global climate change: potential effects on U.S. resources. Pew Center on Global Climate Change, Arlington, VA

McRoy CP, McMillan C (1977) Production ecology and physiology of seagrasses. In: McRoy CP, Helfferich C (eds) Seagrass ecosystems. Marcel Dekker, New York

Moloney KA, Levin SA (1996) The effects of disturbance architecture on landscape-level population dynamics. Ecology 77:375-394

Moore KA, Orth RJ, Novak JF (1993) Environmental regulation of seed germination in Zostera marina L. (eelgrass) in Chesapeake Bay: effects of light, oxygen and sediment burial. Aquat Bot 45:79-91

Neckles HA, Short FT, Barker S, Kopp BS (2005) Disturbance of eelgrass Zostera marina by commercial mussel Mytilus edulis harvesting in Maine: dragging impacts and habitat recovery. Mar Ecol Prog Ser 285:57-73

NMFS (National Marine Fisheries Service) (2001) Endangered Species Act Section 7 Consultation and MagnusonStevens Act Essential Fish Habitat Consultation Programmatic Biological Opinion. 15 Categories of Activities Requiring Department of the Army Permits. OSB20010016, Army Corps of Engineers, Portland District

Orth RJ, Fishman JR, Wilcox DJ, Moore KA (2002) Identification and management of fishing gear impacts in a recovering seagrass system in the coastal bays of the Delmarva Peninsula, USA. J Coast Res 37:111-129

Orth RJ, Harwell MC, Inglis GJ (2006a) Seagrass seeds and dispersal strategies. In: Larkum AWD, Orth RJ, Duarte CM (eds) Seagrasses: biology, ecology and conservation. Springer, Dordrecht, p 111-133

Orth RJ, Luckenbach ML, Marion SR, Moore KA, Wilcox DJ (2006b) Seagrass recovery in the Delmarva Coastal Bays, USA. Aquat Bot 84:26-36

Peterson BJ, Heck KL Jr (1999) The potential for suspension feeding bivalves to increase seagrass productivity. J Exp Mar Biol Ecol 240:37-52

Peterson BJ, Heck KL Jr (2001) Positive interactions between suspension-feeding bivalves and seagras - a facultative mutualism. Mar Ecol Prog Ser 213:143-155

Editorial responsibility: Otto Kinne (Editor-in-Chief), Oldendorf/Luhe, Germany
Peterson CH, Summerson HC, Fegley SR (1987) Ecological consequences of mechanical harvesting of clams. Fish Bull 85:281-298

Phillips RC (1984) The ecology of eelgrass meadows in the Pacific Northwest: a community profile. FWS/OBS-84/24, US Fish \& Wildlife Service, Washington, DC

Plus M, Deslous-Paoli JM, Dagault F (2003) Seagrass (Zostera marina L.) bed recolonisation after anoxia-induced full mortality. Aquat Bot 77:121-134

Pregnall MM (1993) Regrowth and recruitment of eelgrass (Zostera marina) and recovery of benthic community structure in areas disturbed by commercial oyster culture in the South Slough National Estuarine Research Reserve, Oregon. MSc thesis, Bard College, Annandale-On-Hudson, NY

Quayle DB, Newkirk GF (1989) Farming bivalve molluscs: methods for study and development. World Aquaculture Society, Baton Rouge, LA

Reusch TBH, Chapman ARO, Gröger JP (1994) Blue mussels Mytilus edulis do not interfere with eelgrass Zostera marina but fertilize shoot growth through biodeposition. Mar Ecol Prog Ser 108:265-282

Robertson AI, Mann KH (1984) Disturbance by ice and lifehistory adaptations of the seagrass Zostera marina. Mar Biol 80:131-141

Ruesink JL, Roegner GC, Dumbauld BR, Newton JA, Armstrong D (2003) Contributions of oceanic and watershed energy sources to secondary production in a northeast Pacific estuary. Estuaries 26:1079-1093

Ruesink JL, Feist BE, Harvey CJ, Hong JS, Trimble AC, Wisehart LM (2006) Changes in productivity associated with four introduced species: ecosystem transformation of a 'pristine' estuary. Mar Ecol Prog Ser 311:203-215

Short FT, Burdick DM (1996) Quantifying seagrass habitat loss in relation to housing development and nitrogen loading in Waquoit Bay, Massachusetts. Estuaries 19:730-739

Short FT, Wyllie-Echeverria S (1996) Natural and human-induced disturbance of seagrasses. Environ Conserv 23: 17-27

Simenstad CA, Fresh KL (1995) Influence of intertidal aquaculture on benthic communities in Pacific Northwest estuaries: scales of disturbance. Estuaries 18:43-70

Thayer GW, Kenworthy WJ, Fonseca MS (1984) The Ecology of eelgrass meadows of the Atlantic Coast: a community profile. FWS/OBS-84/02, USFWS

Thom RM, Borde AB, Rumrill S, Woodruff DL, Williams GD, Southard JA, Sargent SL (2003) Factors influencing spatial and annual variability in eelgrass (Zostera marina L.) meadows in Willapa Bay, Washington, and Coos Bay, Oregon. Estuaries 26:1117-1129

Waddell JE (1964) The effect of oyster culture on eelgrass (Zostera marina L.) growth. MSc thesis, Humboldt State College, Arcata, CA

Submitted: July 28, 2006; Accepted: February 20, 2007 Proofs received from author(s): July 29, 2007 